\title{
Phosphorus, Cold Fire, Wonder Pills, and the Birth of the Match Industry
}

In about 1675 , the German alchemist Hennig Brandt attempted to extract gold from urine whose color suggested to him that it harbored the coveted metal. A contemporary and rival who recorded his method shows that Brandt followed the putrefy-then-purify strategy of alchemical transmutations. After evaporating the urine down, the fetid residue was left to putrefy for months. Brandt then transferred the foul result to a retort, added a good portion of sand, and attached the end of the retort to a receiving basin of water. He then let the purifying powers of heat do its work. According to his alchemical intuition, the golden color of the original ingredient ought to have shown up as golden glitter when the vapors from the retort condensed into the cold receiving water. It didn't.

His alchemical failure, however, was not complete. The vapors did in fact condense-not into gold, but into a white and waxy substance with some astounding properties. When the water was removed and the underlying paste exposed to the air, the material spontaneously ignited. What's more, the material glowed in the dark! Brandt called the stuff "cold fire." The world came to call it phosphorus, from the Greek word meaning giver of light.

Despite the absence of e-mail, word of the discovery spread swiftly. The rare material instantly acquired value like a hot stock and became the focus of drama of seventeenth-century intrigue and deception.

All Brandt knew was that he found a way of making a novel material that could well earn him fame and fortune. In true alchemical form, he tried to guard his manufacturing secrets. But his new phosphorus was kindling the ambitions and attracting the attention of powerful and capable contemporaries.

One of the first to seek the secret of "cold fire" from Brandt was Johann Kunckel, then a famous chemist of Dresden whose last job was as the King of Sweden's Counselor of Metals. Though

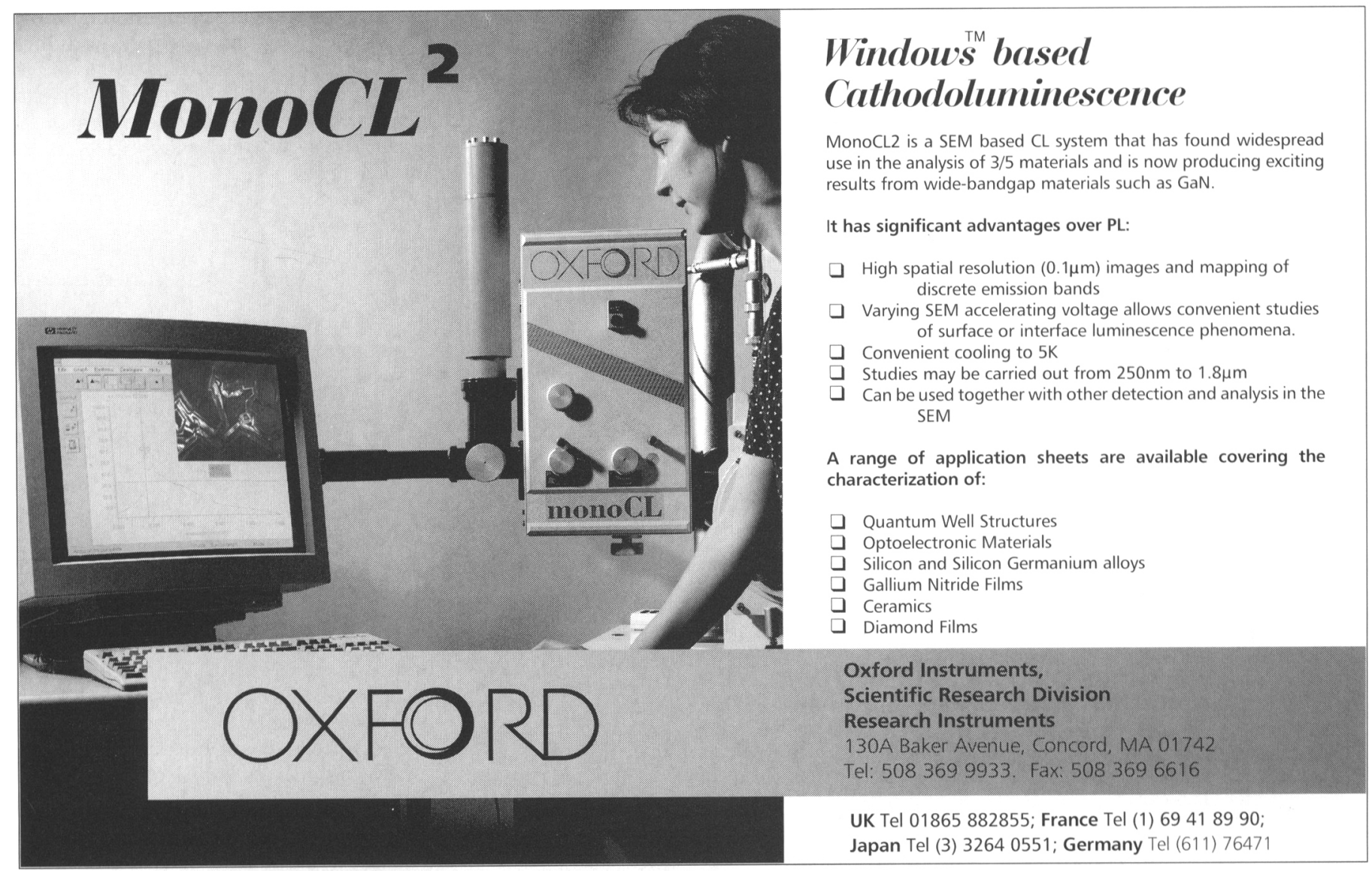


he apparently gave Kunckel some hints, Brandt doggedly refused Kunckel's repeated requests for detailed information about the process.

The plot began to thicken into a tabloid-worthy drama when Kunckel wrote to a Dresden friend, Johann Daniel Krafft, about the situation. As Kunckel recounted in his posthumously published book Laboratorium Chymicum (1716), Krafft secretly traveled to Hamburg and negotiated an equally secret purchase of the glowing novelty. Kunckel only caught wind of the potential intrigue just as he was preparing to leave Hamburg. On the street, he met none other than his old friend Krafft.

Not wasting an opportunity to make money, Krafft traveled from city to city charging money to exhibit the material's seemingly magical properties. In the spring of 1677 , he went to the court at Hanover where he displayed two little glowing vials filled with phosphorus. That visit would trigger a series of events that deflected the history of phosphorus from its alchemical roots into a decided chemical and industrial direction.

Before that, however, Kunckel returned to Dresden where he vowed to use the few clues he did manage to garner from Brandt and his own skills to discover his own route to phosphorus. He succeeded. Kunckel took a medical tack for turning phosphorus into money. "Glowing Wonder Pills" is what he called his product, which he prescribed to adults and children for just about anything that ailed them.

Here was his pitch: "One or two of these pills taken evening and morning will save a man, with the help of God, from all fear of apoplexy or of other sudden sickness during the day. They counteract all noxious and poisoned airs and are a right antidote against the pestilential poison. They strengthen and support the vital spirit in man...." With the help of God is right. He couldn't have been making his pills out of the incendiary phosphorus that Brandt had made. That he could make the pills at all suggests his method produced an allotrope of phosphorus such as red phosphorus that does

\section{For $I S D Q 00 D_{\text {certification }}$}

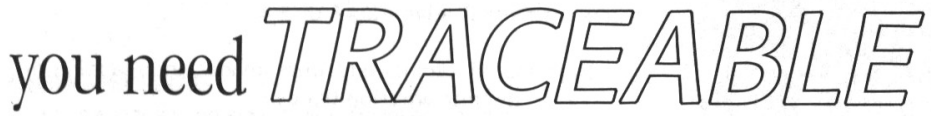

\section{CALIBBAIIION standards $_{\text {s. }}$}

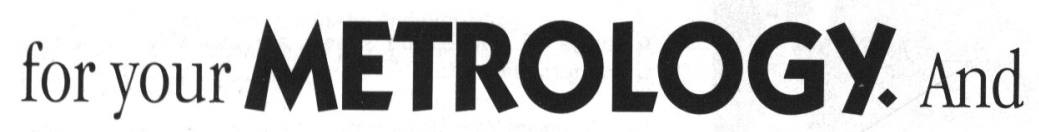

here's the place to get them

Now, get traceable calibration standards and references for Surface Profiling, Film Thickness, Surface Contamination, Surface Characterization, Electrical, and Critical Dimension metrology, and more. Get the free catalog: VLSI Standards, 3087 N. $1^{\text {st. }}$ St., San Jose, CA. 95134. Phone:(408)428-1800 Fax:(408)428-9555.

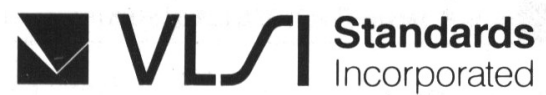

The Measurement Standards for the Industry

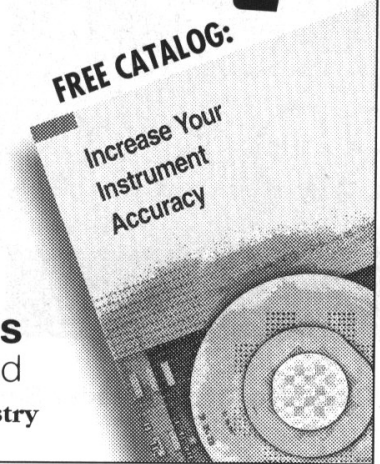

Circle No. 54 on Reader Service Card.

not spontaneously ignite. This may partly explain how Kunckel had the audacity to claim that he, not Brandt, had discovered phosphorus.

At about the same time, Krafft's visit to the Hanover court was beginning to have repercussions. Present was Gottfried Wilhelm Leibniz, the famous philosopher and rival of Newton for the invention of the calculus. Not only was he the court's librarian and historian, but he also was a personal acquaintance of Brandt. Later that year (1677), Leibniz, who eventually wrote his own version of the discovery of phosphorus, arranged for Krafft to perform experiments with the material for members of the Royal Society including Robert Boyle. Afterward, Boyle studied phosphorus more thoroughly.

The following summer, Leibniz mediated a contract between the Duke Johann Friedrich of Hanover and Brandt. The contract called for Brandt to keep Leibniz informed of developments in return for a monthly payment. But soon the Duke of Mecklenburg-Gustrow sent J. Becher, a famous alchemist, to approach Brandt, perhaps for a similar contract. Leibniz, sensing the growing competition, brought Brandt to Hanover where he convinced the Hamburg alchemist to make a fresh supply and finally to reveal the secret process. He later avidly defended Brandt against Kunckel's claim to the discovery of phosphorus.

Brandt's process became general knowledge after Leibniz sent a sample of phosphorus and an account of its production to the Count Ehrenfried Walter von Tschirnhaus in Paris. Tschirnhaus, who later would initiate a systematic research program with the goal of making the European equivalent of then coveted Chinese ceramics, published the BrandtLeibniz method in the history of the Royal Academy.

Boyle, and his assistant Godfrey Hanckwitz, saw phosphorus's potential for an industrial product like matches. The state of the art in portable fire at the time was embodied in the "tinder box." Atop tinder composed of such things as charred linen and cotton threads went a sulfur-covered thread. This collection of dross was then ignited with a spark by striking a piece of flint against an edge of steel. By 1680 , Boyle pushed the industry of portable fire toward phosphorus by demonstrating how phosphorus-laden paper could be made to ignite in the air. The matchlike product, though, was too crude, dangerous, and expensive to become very popular.

For nearly a century the price of phosphorus kept it out of reach for most 
sound entrepreneurial ideas, though many suffered injuries and death in the pursuit of making the element in practical quantities. In 1769, the Swedish pharmacist Carl Scheele discovered a cheap method of producing phosphorus from calcium phosphate in bone. Brandt's cold fire finally became cheap enough for large-scale use and experimentation.

One of the first embodiments was the "phosphoric candle." It consisted of a phosphorus-ridden strip of paper sealed inside of a glass tube. When the tube was broken, the paper would ignite into flame. The dip splint or "instantaneous light box" became a popular variation on this theme, though it did not contain phosphorus. In one version, a set of wooden splints coated in a mix of sugar, gum, and potassium chlorate was placed in one compartment of a case and strong sulfuric acid in the other. The splint was ignited by quickly dipping the splint into the acid.

In the late $1820 \mathrm{~s}$, John Walker of Stockton-on-Tees invented self-contained friction matches, which he called Lucifers, that closely resemble today's matches.
Each was a splint coated with potassium chlorate and antimony sulfide, which would ignite when drawn across sand paper. In the early 1830s, Charles Sauria in France brought phosphorus back into the picture by substituting it for the antimony sulfide. The result was a Lucifer that took less friction to ignite.

The increasing demand for phosphorus-containing matches brought with it a sorry episode in the history of industrial hazards. Many of the young match makers developed a lethal condition called phossy jaw. In 1845 a Viennese chemist made a discovery that would ultimately remove this hazard from the match industry. He found that the white crystalline form of phosphorus in common use could be converted by heat into an amorphous form that was neither as poisonous nor spontaneously ignitable.

Phosphorus began as a breath-taking sideshow of alchemical ambition in the seventeenth-century. Two centuries later, "cold fire" would take its place as element number 15 in the Periodic Table. By then it already had become an enabling material for a new technology-matches as well as for the then-new artificial fertilizers. By the 20th century, phosphorus had become not only a staple for a plethora of military, agricultural, and industrial products, but its central and splendid role in the biochemistry of life was being revealed. What would Brandt have thought had he known what would come from his lust for gold?

IVAN AMATO

For Further REAdiNG: M.E. Weeks, "Discovery of the Elements," Journal of Chemical Education (Washington, DC, 1956); P.G. Beery, Stuff: The Story of Materials in the Science of Man (D. Appleton and Company, New York, 1930); J.N. Friend, Man and the Chemical Elements (Charles Scribner's Sons, New York, 1961); T.K. Derry and T.I. Williams, A Short History of Technology (Dover Publications, New York, 1993), originally published by the Oxford University Press in 1960; A. D.F. Toy and E.N. Walsh, Phosphorus Chemistry in Everyday Living (American Chemical Society, Washington, DC, 1987).

\section{MULTI-FILM DEPOSITION CONTROL}

\section{STC-200/SQ CONTROLLER STM-100/MF MONITOR}

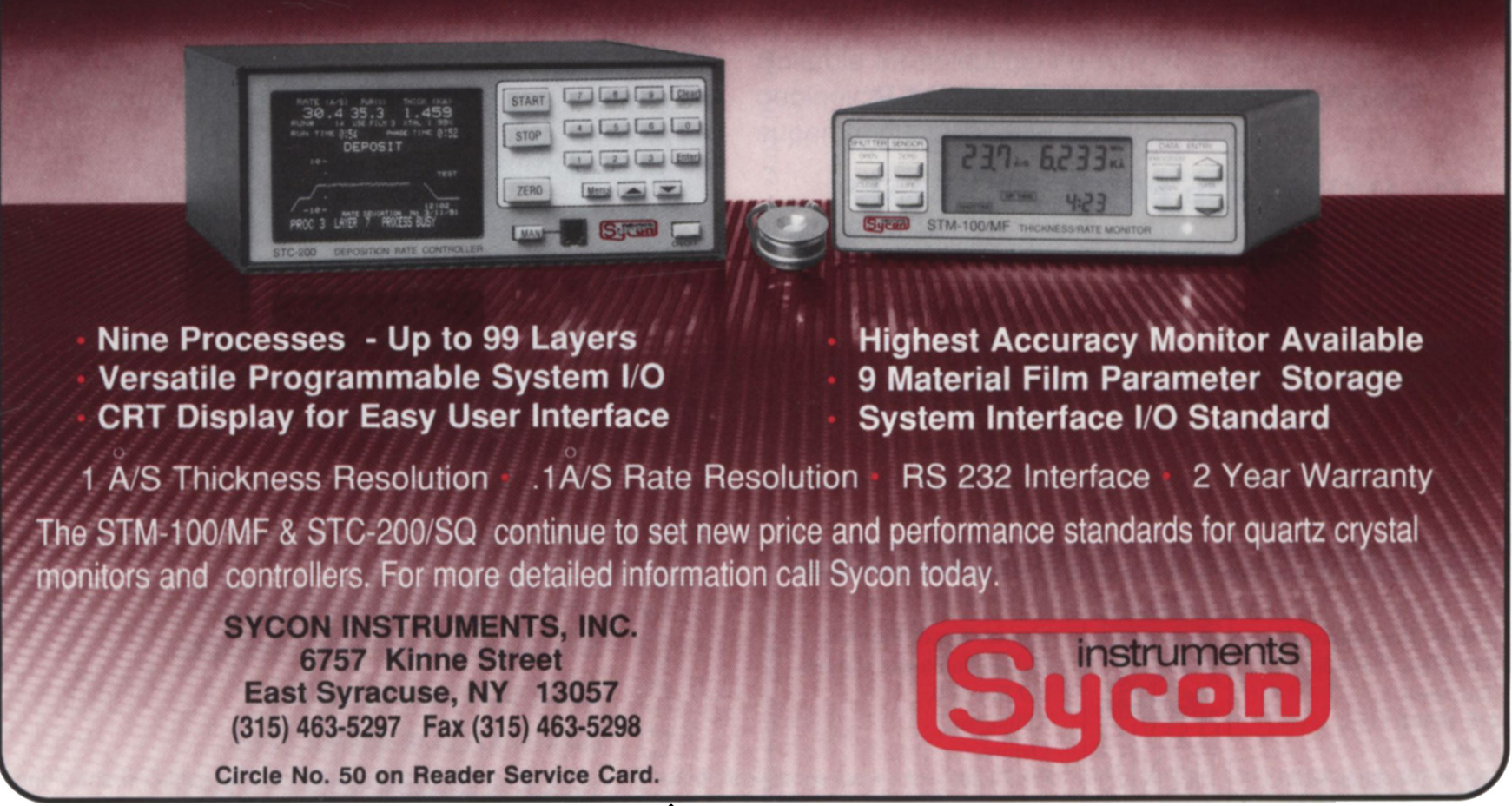




\section{TRENDS IN POLYMER SCIENCE}

THE MONTHLY POLYMER UPDATE AT YOUR FINGERTIPS!

An invaluable
resource

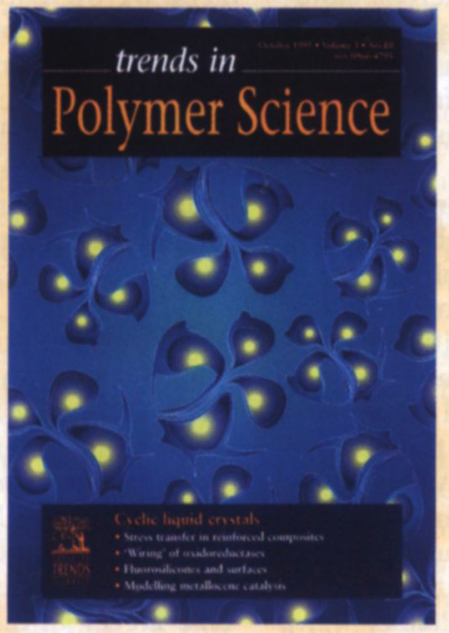

REVIEWING THE FIELD OF POLYMER RESEARCH

Trends in Polymer Science focuses on the most important international developments in macromolecular research,

highlighting innovative areas of $\mathrm{R} \& \mathrm{D}$ by inviting expert authors to distil recent advances into readable, informative articles and to evaluate the likely future industrial applications.

- Commissioned by the in-house Editor, with input from the International Advisory Editorial Board

- Written by experts with specialist knowledge in the field

- Peer-reviewed to ensure balance and accurate coverage

- Edited by in-house staff for clarity and readability

- Thoroughly referenced to guide you towards further relevant literature

\section{PHONE OR FAX YOUR ORDER} BEFORE DECEMBER 31st

\section{TO AVOID 1996 PRICE INCREASES!}

\section{MONTHLY ISSUES FOR ONLY:}

1995 Personal Subscription $£ 72.00 / U S \$ 115.00$

1995 Student Subscription (50\% discount) $\mathbf{£ 3 6 . 0 0 / U S \$ 5 8 . 0 0}$ 1995 Institutional Subscription $£ 345.00 /$ US\$14.00 includes a hard-bound annual compendium.

For your free sample copy score the appropriate box on the right!

\section{FOR FURTHER INFORMATION:}

\section{THE AMERICAS}

Elsevier Trends Journals,

660 White Plains Road,

Tarrytown,

NY 10591-5153,

USA

Tel: +1 (914) 5249200

Fax: $+1(914) 3332444$

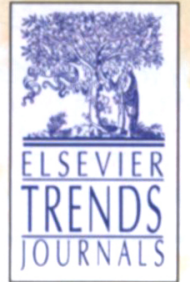

EUROPEAN/ROW

Elsevier Trends Journals,

Oxford Fulfilment Centre,

PO Box 800

Kidlington,

Oxford

OX5 1DX

Tel: +44 (1865) 843300

Fax: $+44(1865) 843940$
ELSEVIER POLYMER JOURNALS-

ESSENTIAL TOOLS FOR POLYMER RESEARCH

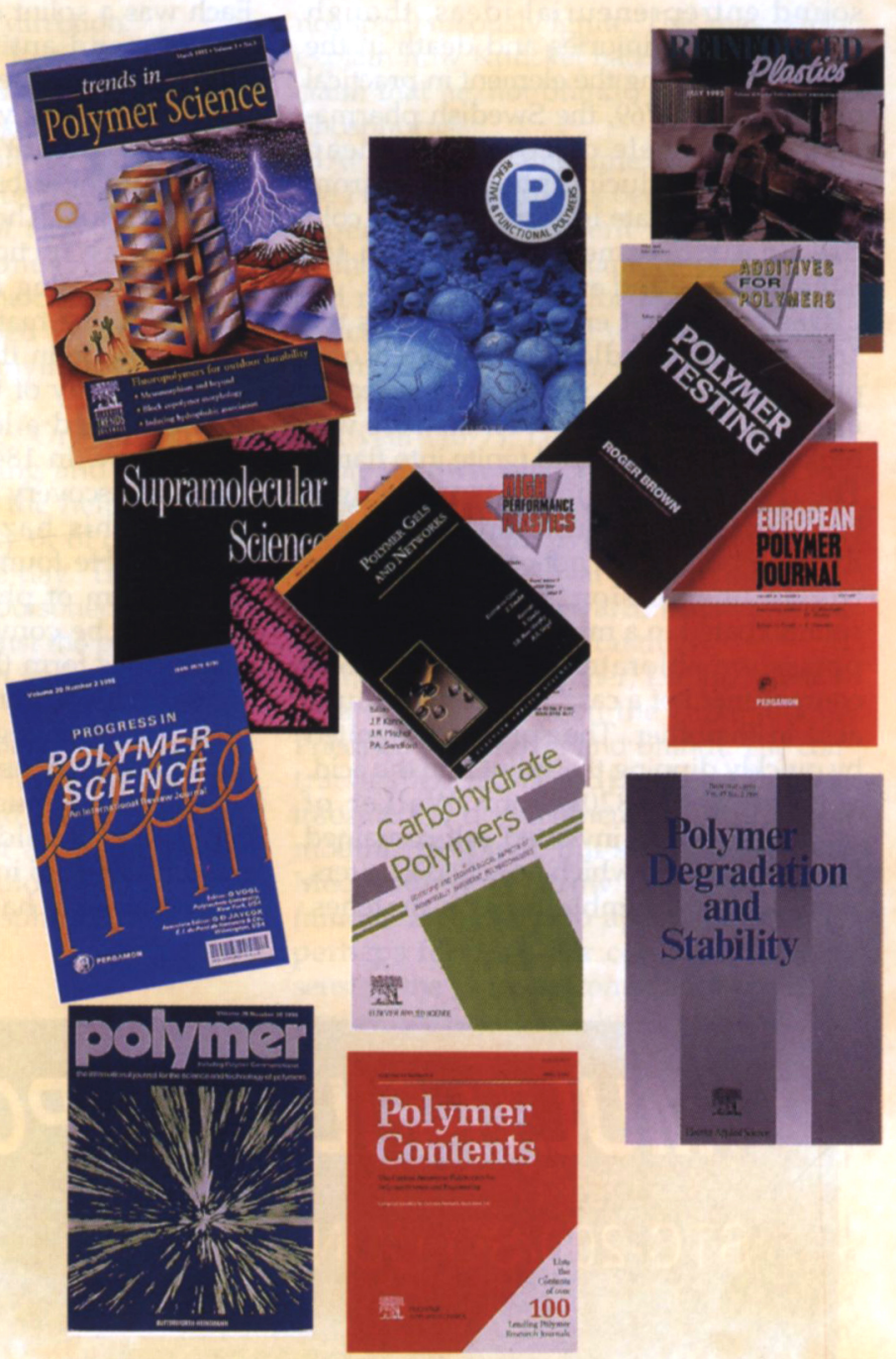

Please send me a free sample copy of

ADDITIVES FOR POLYMERS (2061)

CARBOHYDRATE POLYMERS (2011)

EUROPEAN POLYMER JOURNAL (294)

HIGH PERFORMANCE PLASTICS (2085)

POLYMER (3078)

POLYMER CONTENTS (2049)

POLYMER DEGRADATION AND STABILITY (2045)

POLYMER GELS AND NETWORKS (2047)

POLYMER TESTING (2050)

PROGRESS IN POLYMER SCIENCE (418)

REACTIVE AND FUNCTIONAL POLYMERS

REINFORCED PLASTICS (2104)

SUPRAMOLECULAR SCIENCE (3082)

TRENDS IN POLYMER SCIENCE (2126) 


\section{Finally - A powerful X-ray diffraction system for microanalysis that's flexible, too!}

Siemens' HI-STAR area detector with General Area Detector Diffraction System (GADDS) software provides you with a more powerful, faster and more flexible microdiffraction system than any other commercially available. Combined laser and video sample alignment provides real-time color displays of both the diffraction pattern and the region under investigation (shown below). These regions can be selected manually, with "point and shoot" capabilities, or in pre-defined arrays, permitting Diffraction Function Mapping (DFM) studies.

- Ideal for studying very small samples, or micro-defects on large samples.

- Fast data collection with HI-STAR, Siemens' unique 2-dimensional detector technology.

- An optional crossed Göbel mirror system can provide increased $X$-ray flux, eliminating the need for a rotating anode $\mathrm{X}$-ray source.
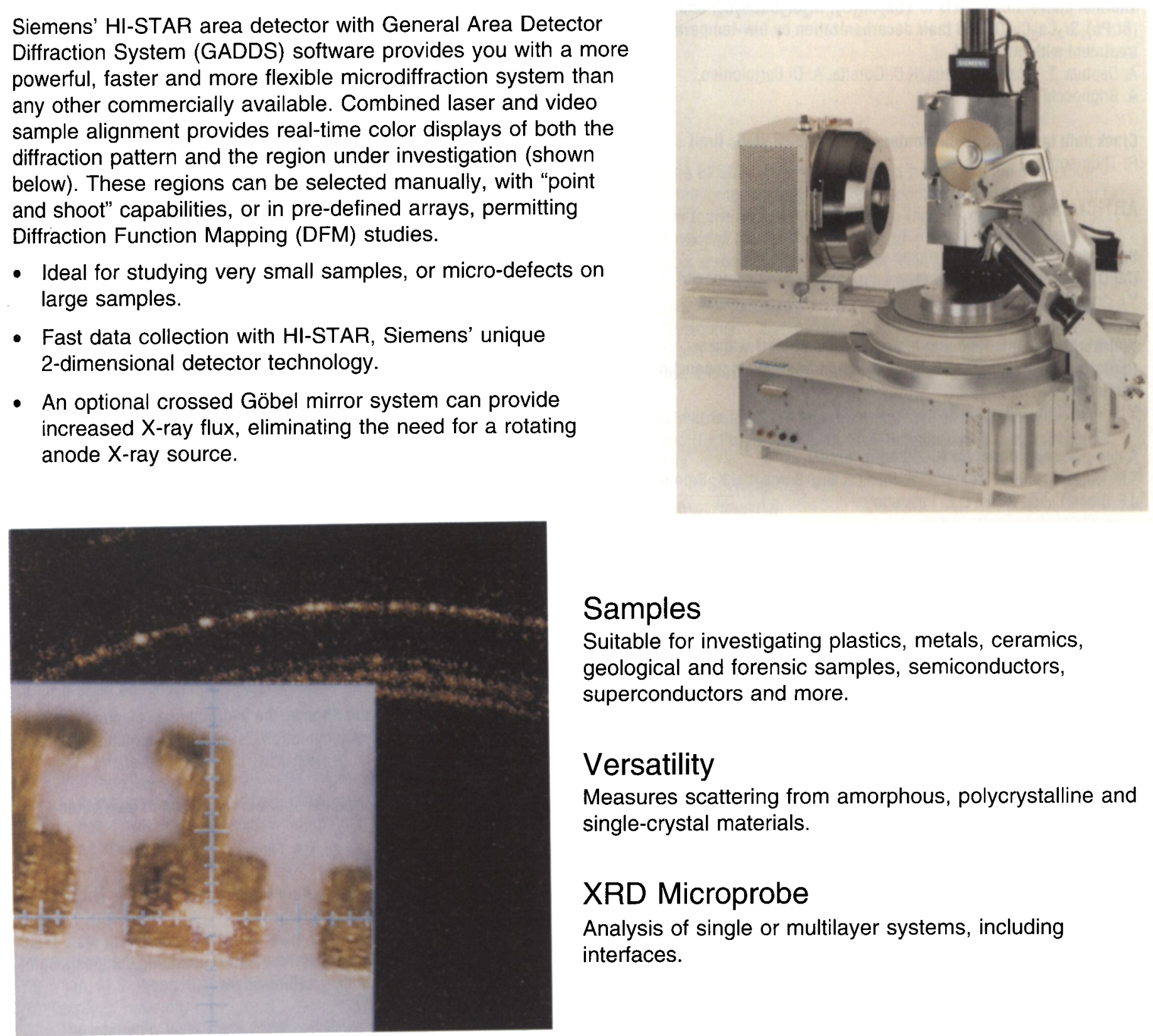

\section{Samples}

Suitable for investigating plastics, metals, ceramics, geological and forensic samples, semiconductors, superconductors and more.

\section{Versatility}

Measures scattering from amorphous, polycrystalline and single-crystal materials.

\section{XRD Microprobe}

Analysis of single or multilayer systems, including interfaces. 